\title{
In situ ETEM synthesis of NiGa alloy nanoparticles from nitrate salt solution
}

Damsgaard, Christian Danvad; Duchstein, Linus Daniel Leonhard; Sharafutdinov, Irek; Nielsen, Morten Godtfred; Chorkendorff, Ib; Wagner, Jakob Birkedal

Published in:

Journal of Electron Microscopy

Link to article, DOI:

10.1093/jmicro/dfu025

Publication date:

2014

Document Version

Publisher's PDF, also known as Version of record

Link back to DTU Orbit

Citation (APA):

Damsgaard, C. D., Duchstein, L. D. L., Sharafutdinov, I., Nielsen, M. G., Chorkendorff, I., \& Wagner, J. B. (2014). In situ ETEM synthesis of NiGa alloy nanoparticles from nitrate salt solution. Journal of Electron Microscopy, 63(5), 397-401. https://doi.org/10.1093/jmicro/dfu025

\section{General rights}

Copyright and moral rights for the publications made accessible in the public portal are retained by the authors and/or other copyright owners and it is a condition of accessing publications that users recognise and abide by the legal requirements associated with these rights.

- Users may download and print one copy of any publication from the public portal for the purpose of private study or research.

- You may not further distribute the material or use it for any profit-making activity or commercial gain

- You may freely distribute the URL identifying the publication in the public portal 


\title{
In situ ETEM synthesis of NiGa alloy nanoparticles from nitrate salt solution
}

\section{Christian Danvad Damsgaard 1,2,* , Linus Daniel Leonhard Duchstein ${ }^{1}$, Irek Sharafutdinov ${ }^{2}$, Morten Godtfred Nielsen², Ib Chorkendorff ${ }^{2}$ and Jakob Birkedal Wagner ${ }^{1}$}

${ }^{1}$ Center for Electron Nanoscopy, Technical University of Denmark, DK-2800 Kongens Lyngby, Denmark, and ${ }^{2}$ CINF, Department of Physics, Technical University of Denmark, DK-2800 Kongens Lyngby, Denmark

*To whom correspondence should be addressed. E-mail: christian.damsgaard@cen.dtu.dk

Received 23 December 2013; Accepted 19 June 2014

\begin{abstract}
Metallic alloy nanoparticles (NPs) are synthesized in situ in an environmental transmission electron microscope. Atomic level characterization of the formed alloy NPs is carried out at synthesis conditions by use of high-resolution transmission electron microscopy, electron diffraction and electron energy-loss spectroscopy.
\end{abstract}

Key words: sample preparation, high resolution, environmental TEM, gas reaction, microscopy, catalysis

\section{Introduction}

Industrial catalysts based on metal alloy nanoparticles (NPs) are usually synthesized chemically by dispersing the NPs on a high surface area porous 3D support in order to increase the active surface area [1]. Electron microscopy $(\mathrm{EM})$ is an excellent tool to provide important information on size, morphology and dispersion of such NP-based catalysts on the local scale [2-5]. However, the morphology of the support may complicate interpretation of EM images of the catalyst on the atomic level due to limited depth of field.

One way to circumvent this is to synthesize the NPs on an electron transparent 2D support representing the high surface area 3D support of the large scale catalyst [6]. Fundamental studies of catalysts NPs and the gas-solid interaction studies performed in the environmental transmission electron microscope (ETEM) benefit significantly by having a less complex model catalyst, which is representative for the 'real' large scale catalyst system [7-11]. Changing the synthesis procedure might, however, change the alloy properties such as the chemical composition or the particle size distribution significantly and no longer resemble the 'real' catalysts in a desired way.

The present study shows an easy route to form alloy NPs on a 2D support in situ in an ETEM by use of the same synthesis recipe as the corresponding large scale prepared high surface area 3D supported catalyst. As a proof-of-concept, this work presents results on Ni-Ga NPs which have proved highly active as a catalyst for methanol synthesis [12, I. Sharafutdinov, submitted for publication]. The same approach has been used to form other alloy NPs in the ETEM such as CuNi and PdGa.

\section{Materials and methods}

Sample preparation was performed by impregnating a plasma cleaned $20 \mathrm{~nm} \mathrm{SiO}_{x}$ membrane suspended on a TEM grid (Temwindows.com and plano-em.de) with a mixed aqueous solution of nickel and gallium nitrates (Sigma Aldrich) in the $\mathrm{Ni}$ : Ga molar ratio of $5: 3$ and subsequently heated in hydrogen flow at a temperature between 600 and $700^{\circ} \mathrm{C}$. This exact 
impregnation method has successfully been used to form highly active alloy NPs on 3D high surface area $\mathrm{SiO}_{2}$ (Saint Gobain NORPRO, $241 \mathrm{~m}^{2} / \mathrm{g}$ ) [I. Sharafutdinov, submitted for publication]. According to the phase diagram of $\mathrm{Ni}-\mathrm{Ga}$ alloys, the orthorhombic $\delta$-phase is the most stable phase in the present temperature and composition range [13].

The $2 \mathrm{D} \mathrm{SiO}_{x}$ membrane was chosen in order to resemble the same material as the $3 \mathrm{D}$ high surface area $\mathrm{SiO}_{2}$ support.

Three different methods of impregnation were conducted in order to disperse the solution on the 2D support and achieve a sample with a high particle coverage and a narrow size distribution comparable to the characteristics of the 3D supported catalyst:

(i) drop casting (d.c.) followed by drying in air: $\mathrm{Ni}-\mathrm{Ga}_{\text {air }}$,

(ii) d.c. followed by a spin coater step: $\mathrm{Ni}-\mathrm{Ga}_{\text {spin }}$ and

(iii) d.c. followed by a freeze drying step: $\mathrm{Ni}-\mathrm{Ga}_{\text {freeze }}$.

The spin coating was performed on a conventional spin 150 coater at $4000 \mathrm{rpm}$ for $60 \mathrm{~s}$. The freeze drying took place in a home-made device consisting of a Peltier element in contact with a copper plate (Fig. 1). The Peltier element is water cooled on the backside, and dry nitrogen carries the humid air away during sublimation. The sublimation was performed at $-12^{\circ} \mathrm{C}$ for 2 days.
After the final step following the d.c. as described above, the TEM grids were dried in air at RT for several hours and subsequently loaded in a Philips TEM heating holder and inserted in an aberration-corrected FEI Titan 80-300 ETEM operated at $300 \mathrm{kV}$ [14]. The images are obtained at Scherzer focus with $\mathrm{C}_{\mathrm{s}}<50 \mu \mathrm{m}$. The particle formation was performed in situ at $\sim 650^{\circ} \mathrm{C}$ in $130 \mathrm{~Pa} \mathrm{H}_{2}$ in the microscope.

\section{Results and discussion}

Figures 2 and 3 show the formation of particles during heating in case of the $\mathrm{Ni}-\mathrm{Ga}_{\text {air }}$ and $\mathrm{Ni}-\mathrm{Ga}_{\text {freeze }}$ samples, respectively. The field of view is the same in Figs. 2 and 3, respectively. The large variations in contrast obtained for $\mathrm{NiGa}_{\text {air }}$ at RT shown in Fig. $2 \mathrm{a}$ are due to inhomogeneous dispersion of the nitrate salt. At $300^{\circ} \mathrm{C}$, small particles are formed as observed in Fig. 2 b. At $660^{\circ} \mathrm{C}$, larger particles are formed. The same particle formation mechanism is observed for $\mathrm{NiGa}_{\text {freeze }}$ as shown in Fig. 3; however, the nitrate salt distribution is much more homogenous and do not give variation in contrast in Fig. 3a.

The final NP size distribution and dispersion varies significantly with the preparation method as it is dependent
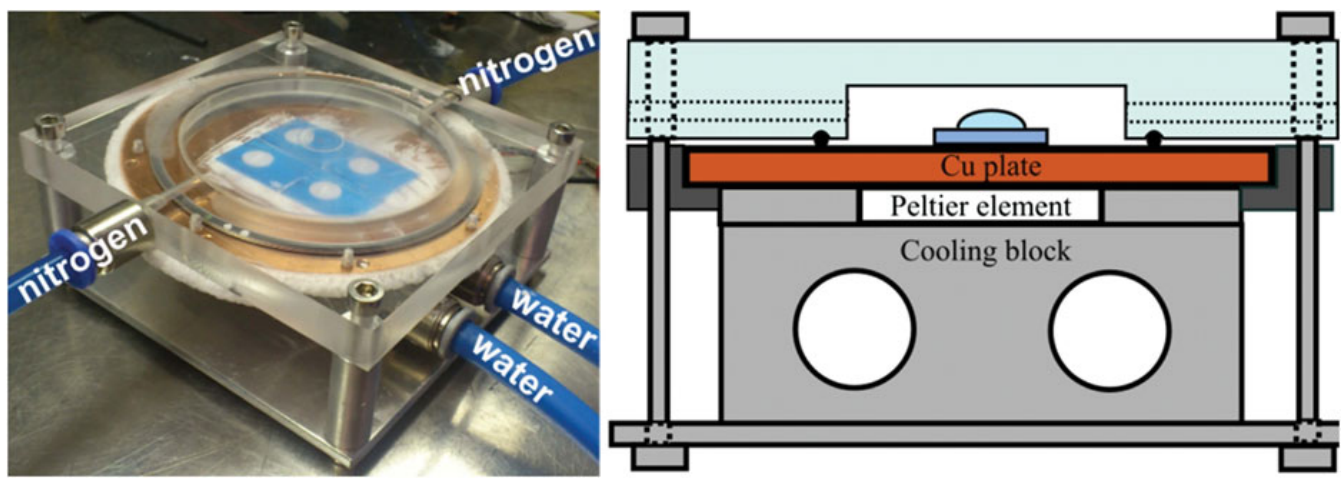

Fig. 1. Photo and schematic representation of the device used for sublimation.
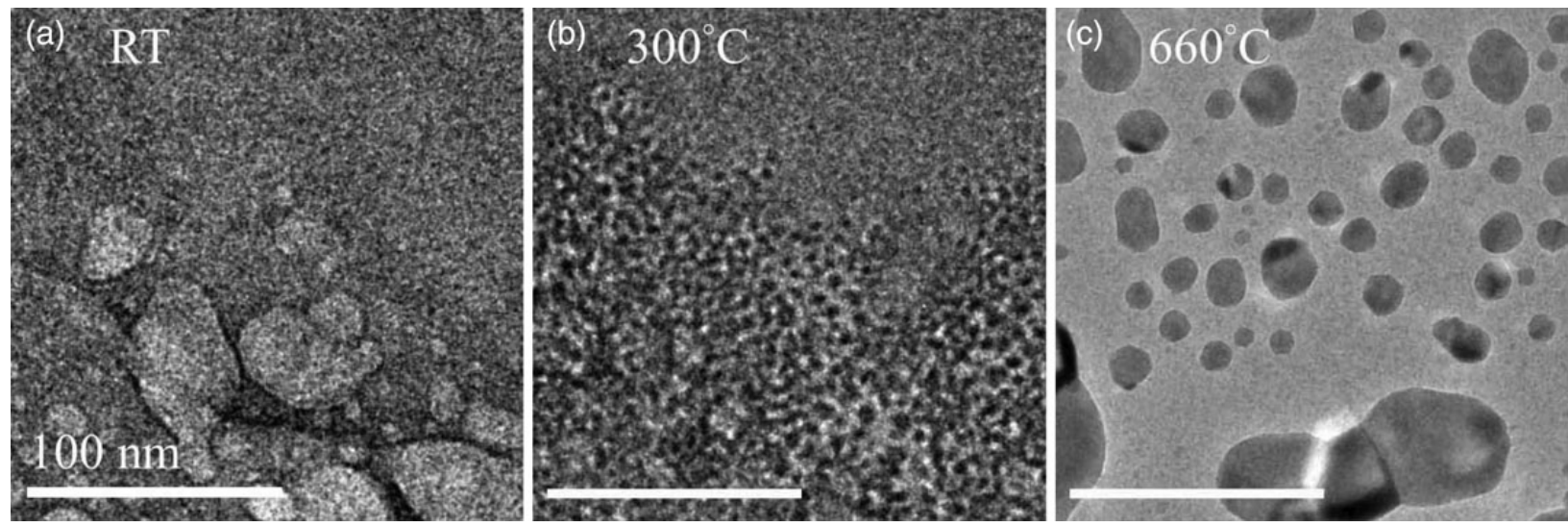

Fig. 2. TEM images of sample $\mathrm{Ni}-\mathrm{Ga}_{\text {air }}$ during NP formation in $130 \mathrm{~Pa} \mathrm{H}_{2}$ at (a) room temperature, (b) $300^{\circ} \mathrm{C}$ and (c) $660^{\circ} \mathrm{C}$, respectively. 

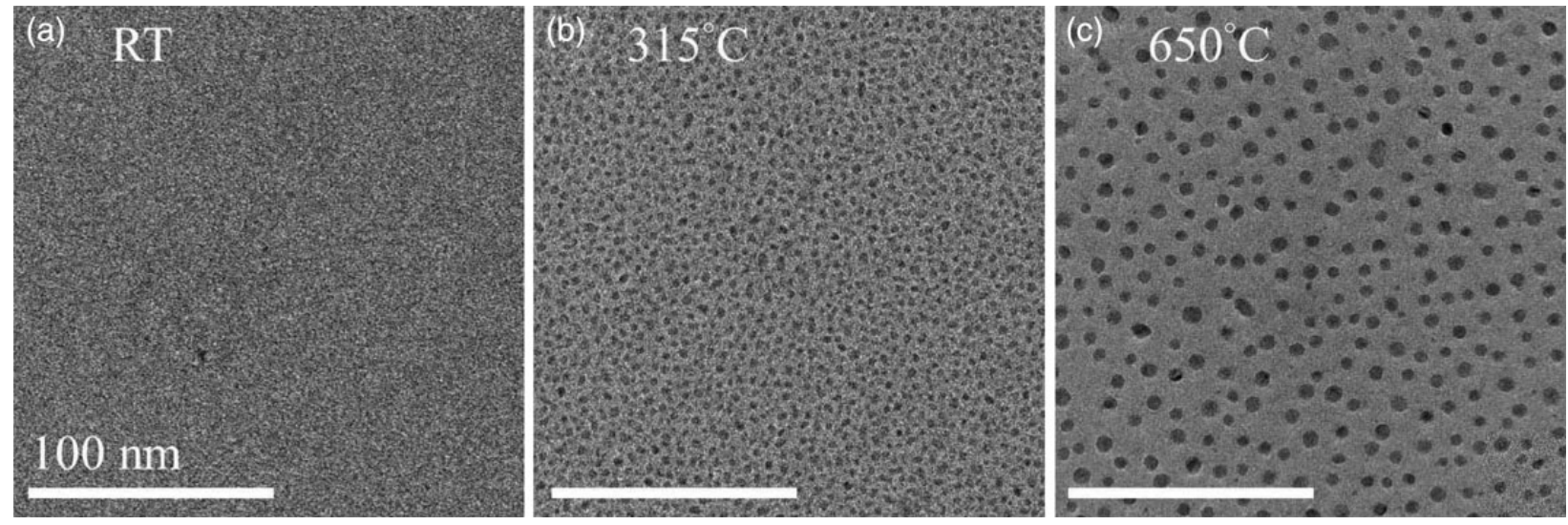

Fig. 3. TEM images of sample $\mathrm{Ni}-\mathrm{Ga}_{\text {freeze }}$ during NP formation in $130 \mathrm{~Pa} \mathrm{H}_{2}$ at (a) room temperature, (b) $315^{\circ} \mathrm{C}$ and (c) $650^{\circ} \mathrm{C}$, respectively.
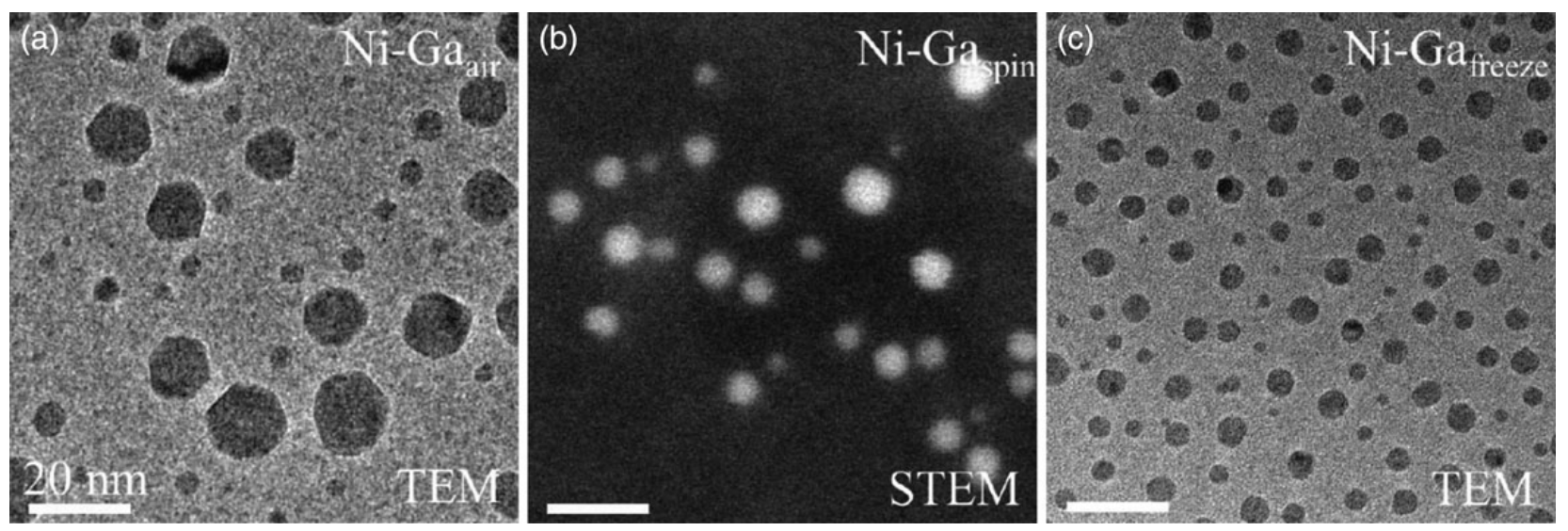

Fig. 4. (S)TEM images of $\mathrm{Ni}-\mathrm{Ga}_{\text {air }}$ (a), $\mathrm{Ni}-\mathrm{Ga}_{\text {spin }}$ (b) and $\mathrm{Ni}-\mathrm{Ga}_{\text {freeze }}$ (c) after $\mathrm{NP}$ formation in $130 \mathrm{~Pa}_{2}$ at $650^{\circ} \mathrm{C}$.

on the initial distribution of the salt nitrate. As observed in Figs. $2 \mathrm{a}$ and $3 \mathrm{a}$, the initial salt nitrate distribution is clearly different in the two cases. In the $\mathrm{Ni}-\mathrm{Ga}_{\text {air }}$ sample, the initial distribution of the precursor material is driven by the surface tension of the liquid salt solution deposited onto the $\mathrm{SiO}_{x}$ membrane. Furthermore, the exposed area of the TEM grid decreases as the droplet evaporates and thus moves the precursor towards the middle of the initial droplet. During this process precursor material is deposited around inhomogeneities on the $\mathrm{SiO}_{x}$ membrane surface resulting in areas with relatively high precursor concentration as seen in Fig. 2a. NPs of various sizes are formed when reaching a temperature of $300^{\circ} \mathrm{C}$. The varying concentration of nitrate salt in the droplet results in the formation of differently sized particles as higher concentration of salt results in larger particles.

In the sample, $\mathrm{Ni}-\mathrm{Ga}_{\text {spin }}$, the initial distribution of the precursor material is driven by the formation of a thin precursor material layer across the complete TEM grid, evaporating during the spinning process. Inhomogeneities on the $\mathrm{SiO}_{x}$ membrane surface influence on the thickness of the
Table 1. Coverage and average particle size for 3D high surface area $\mathrm{SiO}_{2}$-supported $\mathrm{NiGa}$ catalyst and $\mathrm{Ni}-\mathrm{Ga}_{\text {freeze, }}$ respectively

\begin{tabular}{lll}
\hline & Coverage $\left(\right.$ particles $\left./ \mathrm{m}^{2}\right)$ & Particle size $(\mathrm{nm})$ \\
\hline 3D supported NiGa NPs & $1.3 \times 10^{15}$ & $5.2 \pm 1.5$ \\
2D supported Ni-Ga freeze & $7.6 \times 10^{15}$ & $4.9 \pm 1.5$ \\
\hline
\end{tabular}

The coverage of the 3D supported catalyst is calculated from the total mass of $\mathrm{Ni}$ and $\mathrm{Ga}$, the surface area of the support, the density of the $\mathrm{Ni}_{5} \mathrm{Ga}_{3} \delta$-phase and the average particle size.

precursor layer and thus changes the precursor concentration, but to a lesser degree than for $\mathrm{Ni}-\mathrm{Ga}_{\text {air }}$.

The initial distribution of the precursor material in the $\mathrm{Ni}-\mathrm{Ga}_{\text {freeze }}$ is driven by the immediate freezing of the droplet. The water is removed from the solution by sublimation without changing the initial area of precursor material. In this way, the final salt distribution is very homogeneous and independent on the surface tension and inhomogeneities on the TEM grid surface. 

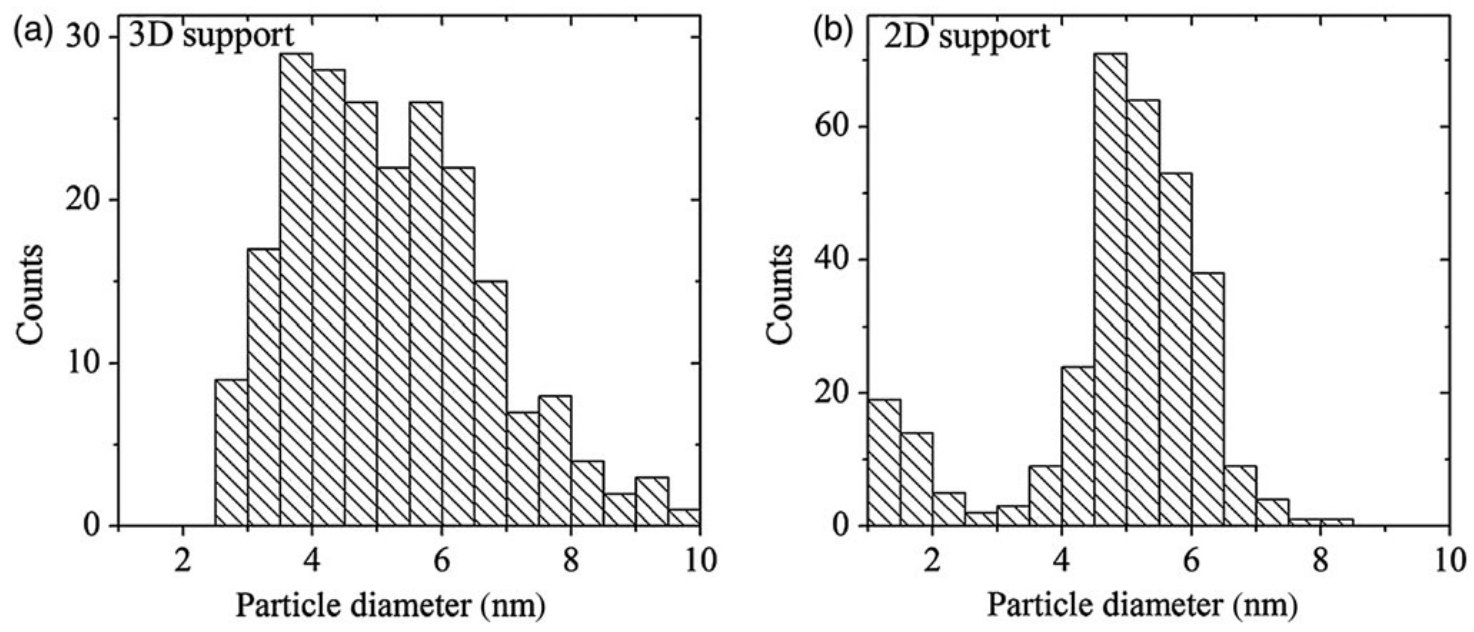

Fig. 5. Size distribution histograms of 219 3D supported NPs (a) and $3182 \mathrm{D}$ supported NPs (b). The diameters have been estimated by calculating the diameter of a circle with an area equivalent to the particle cross-sections measured by TEM.

(a)

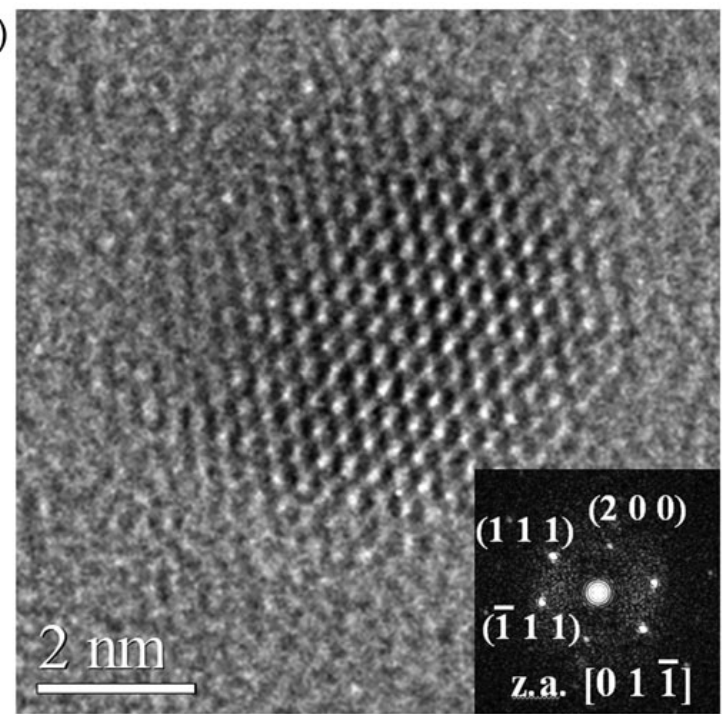

(b)

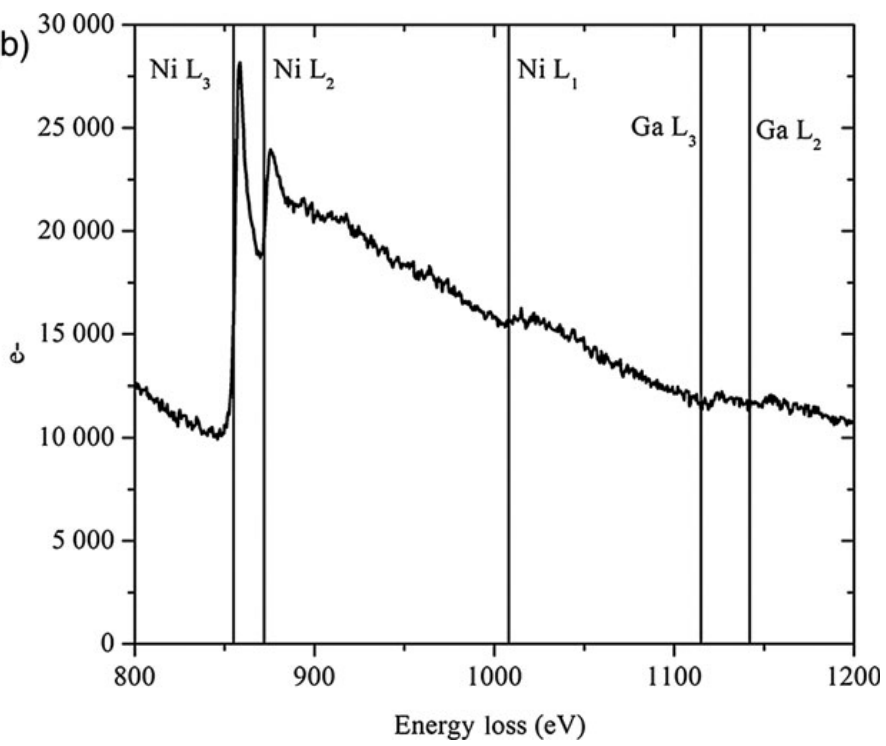

Fig. 6. High-resolution TEM image of a NP after the reduction cycle as well as an fast Fourier transform (FFT) of the NP region reveals a orthorhombic structure resembling the $\mathrm{Ni}-\mathrm{Ga} \delta$-phase. The crystal is viewed along the $[01 \overline{1}]$ zone axis. STEM-EELS of single nanoparticle. The $\mathrm{Ni} \mathrm{L}_{2,3}, \mathrm{Ni} \mathrm{L}_{1}$ and $\mathrm{Ga}$ $L_{2,3}$ ionization edges are clearly visible.

Figure 4 shows TEM images of $\mathrm{Ni}-\mathrm{Ga}_{\mathrm{air}}, \mathrm{Ni}-\mathrm{Ga}_{\text {spin }}$ and $\mathrm{Ni}-\mathrm{Ga}_{\text {freeze }}$ after NP formation in $130 \mathrm{~Pa} \mathrm{H}_{2}$ at $650^{\circ} \mathrm{C}$. $\mathrm{NiGa}_{\text {air }}$ and $\mathrm{NiGa}_{\text {spin }}$ have a much broader size distribution and a less uniform coverage than $\mathrm{NiGa}_{\text {freeze }}$.

Freeze drying seems to be the best method to resemble the 3D high surface area $\mathrm{SiO}_{2}$-supported catalyst regarding coverage of NPs, particle size and size distribution as indicated in Table 1 and Fig. 5. The initial precursor metal concentration was in this case $0.15 \mathrm{~mol} / \mathrm{l}$. The deviance in coverage can to some extent be controlled by controlling the precursor concentration without changing the size distribution of the NPs. Figure 5 shows that 2D supported NPs with similar average size and an even more narrow size distribution than the 3D high surface area $\mathrm{SiO}_{2}$-supported catalyst can be achieved by use of freeze drying.

The orthorhombic $\delta$-phase is found by high-resolution transmission electron microscopy (HRTEM) in all three types of 2D support samples and resembles nicely with the ratio of $\mathrm{Ni}$ and $\mathrm{Ga}$ in the aqueous nitrate solution and the phase found as the active phase in the 3D supported catalyst by in situ x-ray diffraction (XRD) studies [I. Sharafutdinov, submitted for publication]. The general phase composition of $\mathrm{Ni}-\mathrm{Ga}_{\text {freeze }}$ was mapped out by phase analysis of single NPs imaged by HRTEM. The analysis was performed on 11 NPs showing lattice fringes in at least two directions to identify a corresponding crystal structure and zone axis. 
From the analysis, six NPs are uniquely described by the $\delta$-phase, two NPs are uniquely described by the $\beta$-phase, one NP could be described by either $\delta$ or $\beta$-phase and two NPs could be described by either $\delta, \beta$ or $\alpha^{\prime}$-phase. The observed structures could not be explained by metallic or oxidic Ni. A similar phase mixture primarily $\delta$-phase with a small amount of $\alpha^{\prime}$-phase is observed for the high surface area supported NPs by XRD [I. Sharafutdinov, submitted for publication]. Figure 6a shows a characteristic HRTEM image of a NiGa freeze $\mathrm{NP}$ formed during the in situ synthesis. FFT of the image reveals reflections corresponding to the orthorhombic $\mathrm{Ni}-\mathrm{Ga} \delta$-phase along the $[01 \overline{1}]$ zone axis. As an additional indication of the nature of the formed NPs, electron energy-loss spectroscopy (EELS) has been performed on individual NPs formed in the electron microscope. Figure $6 \mathrm{~b}$ shows the EELS signal from a single particle revealing the $\mathrm{Ni}_{2,3}, \mathrm{Ni} \mathrm{L}_{1}$ and $\mathrm{Ga}_{2,3}$ ionization edges. Both the $\mathrm{Ni}$ and $\mathrm{Ga}$ edges are clearly visible and prove that $\mathrm{Ni}$ and $\mathrm{Ga}$ are present in the NP.

\section{Summary}

In summary, the results described in this paper present an easy and efficient way to synthesize an alloy NP 2D model sample in the ETEM, by following a similar synthesis recipe as for large scale synthesized 3D high surface area $\mathrm{SiO}_{2^{-}}$ supported NPs. Three different preparation methods for obtaining a homogenous dispersion of NPs have been studied. Drop casting followed by freeze drying results in a particle coverage and particle size distribution similar to the 3D supported catalyst. Individual alloy nanoparticle formation has been studied in the ETEM by means of HRTEM imaging and EELS showing Ni-Ga alloy formation on a 2D support within the same temperature range as the large scale prepared 3D supported catalyst. The hydrogen pressure difference in the two set ups ( 130 vs. $\left.10^{5} \mathrm{~Pa}\right)$ and the morphological difference in the $\mathrm{SiO}_{x}$ support used in the two experiments have no apparent effect on the formation temperature. In order to fully exploit the power of ETEM studies, they have to be complemented by additional studies using different characterization techniques and in the case of catalysts, catalytic tests - preferable on the 2D model catalyst.

\section{Acknowledgements}

The A.P. Møller and Chastine Mc-Kinney Møller Foundation is gratefully acknowledged for the contribution toward the establishment of the Center for Electron Nanoscopy at the Technical University of Denmark. Mr Christian F. Elkjær and Mr Diego Gardini are gratefully acknowledged for fruitful discussions regarding nitrate salt-based precursors for metal alloy NPs and EELS analysis, respectively.

\section{Funding}

For funding of this work, we gratefully acknowledge The Danish Ministry of Science's UNIK initiative CAtalysis for Sustainable Energy (CASE) and The Danish National Research Foundation's Center for Individual Nanoparticle Functionality (DNRF54).

\section{References}

1. Thomas J, Thomas W (1997) Principles and Practice of Heterogeneous Catalysis, (Wiley-VCH, Weinheim).

2. Datye A (2003) Electron microscopy of catalysts: recent achievements and future prospects. J. Catalysis 216: 144-154.

3. Nag N, Liu J, Crozier P A, Li P (2006) In-situ ETEM synthesis of $\mathrm{Ni}-\mathrm{Cu} / \mathrm{TiO}_{2}$ bimetallic catalyst. Microsc. Microanal. 12: 788-789.

4. Liu J J (2011) Advanced electron microscopy of metal-support interactions in supported metal catalysts. ChemCatChem 3: 934-948.

5. Yang J C, Small M W, Grieshaber R V, Nuzzo R G (2012) Recent developments and applications of electron microscopy to heterogeneous catalysis. Chem. Soc. Rev. 41: 8179-8194.

6. van Hardeveld R, Gunter P, van IJzendoorn L, Wieldraaijer W, Kuipers E, Niemantsverdriet J (1995) Deposition of inorganic salts from solution on at substrates by spin-coating: theory, quantification and application to model catalysts. Appl. Surf. Sci. 84: 339-346.

7. Hansen P, Wagner J, Helveg S, Rostrup-Nielsen J, Clausen B, Topsoe H (2002) Atom-resolved imaging of dynamic shape changes in supported copper nanocrystals. Science 295: 2053-2055.

8. Chenna S, Banerjee R, Crozier P A (2011) Atomic-scale observation of the $\mathrm{Ni}$ activation process for partial oxidation of methane using in situ environmental TEM. Chem. Cat. Chem. 3: 1051-1059.

9. Hansen T W, Wagner J B (2012) Environmental transmission electron microscopy in an aberration-corrected environment. Microsc. Microanal. 18: 684-690.

10. Yoshida H, Kuwauchi Y, Jinschek J R, Sun K, Tanaka S, Kohyama M, Shimada S, Haruta M, Takeda S (2012) Visualizing gas molecules interacting with supported nanoparticulate catalysts at reaction conditions. Science 335: 317-319.

11. Damsgaard C, Duchstein L, Gardini D, Wagner J, Sharafutdinov I, Elkjaer C, Dahl S (2012) Probing the deactivation of $\mathrm{NiGa}$ nanoparticles as catalyst for methanol synthesis with environmental TEM. Microsc. Microanal. 18: 1380.

12. Studt F, Sharafutdinov I, Abild-Pedersen F, Elkjaer C F, Hummelshøj J S, Dahl S, Chorkendorff I, Nørskov J K (2014) Discovery of a Ni-Ga catalyst for carbon dioxide reduction to methanol. Nat. Chem. 6: 320-324.

13. Okamoto H (2010) Ga-Ni (Gallium-Nickel). J. Phase Equilib. Diff. 31: 575-576.

14. Hansen T W, Wagner J B, Dunin-Borkowski R E (2010) Aberration corrected and monochromated environmental transmission electron microscopy: challenges and prospects for materials science. Mater. Sci. Technol. 26: 1338-1344. 